\title{
EFFECT OF ADDITIVES IN ArF SINGLE LAYER CHEMICAL AMPLIFICATION PHOTORESIST
}

\author{
MITSUHITO SUWA, TORU KAJITA, AND SHIN-ICHIRO IWANAGA \\ Electronic Material Laboratory, Yokkaichi Research Laboratories \\ Japan Synthetic Rubber Co., Ltd. \\ 100 Kawajiri-cho, Yokkaichi, Mie 510, Japan
}

\begin{abstract}
This paper describes a new approach to the design of positive-tone $\operatorname{ArF}$ single layer chemical amplification (CA) photoresist. The main issue is the effect of small molecular compounds as additives in methacrylic-based ArF CA photoresist. Three alicyclic compounds with adamantyl moiety and two aromatic compounds with naphthyl moiety were selected as additives. Their influences on the photoresist properties were examined and clarified as follows:

- Transparency of the resist film at $193-\mathrm{nm}$ could be controlled by the loading level and the sorts of additives. Alicyclic additives made the resist film more transparent.

- Both the photospeed and the contrast of the resist were drastically influenced by the loaded additives. Enhancement of the photospeed was easily achieved.

- Thermal properties of the resist film could also be affected by additives. However, the effect was generally temperate.

- The loaded additives could mitigate T-top formation of resist profile due to the control of the inherent dissolution rate of the resist.

Loading the additives would compensate some inherent defects of matrix acrylic polymers and consequently allow considerable latitude in resist design of ArF CA resist. A three component system comprising an acrylic polymer, a photoacid generator, and adamantanecarboxylic acid showed good imaging performance $\left(0.26 \mu \mathrm{mL} / \mathrm{S}, 35 \mathrm{~mJ} / \mathrm{cm}^{2}\right)$ on $\mathrm{KrF}$ exposure.
\end{abstract}

\section{Introduction}

ArF excimer laser $(\lambda=193-\mathrm{nm})$ lithography by chemical amplification (CA) photoresists has more recently come to the attention of semiconductor industry because of the expection for manufacturing 1-Gbit DRAMs or microprocessors of sub- $0.2 \mu \mathrm{m}$ CMOS technology. There are, however, too many tasks to overcome in ArF excimer laser lithography, viz. indispensable progresses in resist, reticule, stepper, laser, track, methology, and so on. Especially, the critical area is to be in the field of (single layer) positive-tone photoresist.

In recent five years, many ArF photoresist materials have been proposed including top surface imaging (TSI) resists and multi-layer resists. As to single layer photoresists, IBM-MIT researchers 
demonstrated high imaging performance of acrylic-based CA resist, what they call, Version 1.[1] The Version 1 was optically transparent enough to resolve sub- $0.2 \mu \mathrm{m}$ features, but represented poor etching durability owing to the absence of aromatic rings. In 1992, Fujitsu's researchers first proposed an alicyclic incorporated polymer, "alicyclic polymer", realizing both transparency at 193$\mathrm{nm}$ and good etching durability of the resist.[2] After Fujitsu's milestone in polymer design, Matsushita[3], NEC[4], and IBM-MIT[5] successionally proposed analogous alicyclic polymers. Hence, alicyclic polymer is a key component for single layer photoresists. Among those reported alicyclic polymers, they found an interesting co-incidence; approximately $50 \mathrm{~mole} \%$ of alicyclic segments is required to achieve good etch resistance. Therefore, the resist has to be designed within the remaining only 50 mole\% of segments. However, alicyclic incorporation to the polymer for improving etch resistance is often accompanied by poor aqueous solubility, poor adhesion properties, or unfavorable changing in $\mathrm{Tg}$. The severely degraded imaging performance could not be easily fixed within the only $50 \mathrm{~mol} \%$ budget. Considering the polymer design limitation in two component system ( alicyclic polymer/PAG), a three-component system (alicyclic polymer / steroid dissolution inhibitor / PAG), Version 2, was proposed by IBM-MIT group as a solution for the tradeoff between etching stability and imaging performance.[6] They demonstrated good imaging results with the Version 2 containing 32\% (wt.) of alicyclic carbons.

A new three component system based on another resist design is exhibited in this paper. Not dissolution inhibitor with protective group but dissolution promoter was selected as additives for acrylic-based CA resists. Our objective is to clarify the potentials of a series of additives as tuner for several resist properties, and to propose a novel single layer ArF resist of three component system.

\section{Experimental}

\subsection{Materials}

All organic compounds and solvents were purchased from Aldrich Chemical Company, Inc. or Wako Pure Chemical Industries, Ltd. and used for experiments without further purification. A methacrylic terpolymer was prepared in THF from t-butyl methacrylate (TBMA), methyl methacrylate (MMA), and methacrylic acid (MAA) by thermally induced free-radical polymerization using 2,2'-azobisisobutyronitrile (AIBN) as an initiator.[7] The terpolymer was isolated by precipitation into $n$-hexane, via dropwise addition. The precipitated polymer was filtered, washed with n-hexane and dried in vacuo at $40^{\circ} \mathrm{C}$ for 12 hours. Collected yield was quantitative. The molar ratio of each segment of the polymer was controlled by the feed ratio of each acrylic monomer. The molar composition of terpolymer was TBMA:MMA:MAA $=50: 40: 10$ based on ${ }^{1} \mathrm{H}$ NMR measurement. The terpolymer poly(TBMA-co-MMA-co-MAA) is abbreviated to 541BMA in this paper. $\left(\mathrm{Mw}=83 \mathrm{~K} \mathrm{~g} / \mathrm{mole}, \mathrm{Mw} / \mathrm{Mn}=2.3, \mathrm{Tg}=157^{\circ} \mathrm{C}\right.$ ). Five small molecular compounds, i.e., 1-adamantanol (AdOH), 1-adamantanecarboxylic acid (AdCOOH), 1-adamantaneacetic acid 
( $\left.\mathrm{AdCH}_{2} \mathrm{COOH}\right)$, 1-naphthol ( $\left.\mathrm{NphOH}\right)$, and 1-naphthoic acid $(\mathrm{NphCOOH})$, were used as additives. Photoacid generators (PAGs) were purchased from Midori Kagaku Co., Ltd. and used without further purification. Cyclohexyl methyl (2-oxocyclohexyl) sulfonium trifluoromethanesulfonate (COST) of $2 \%$ (wt.) loading and triphenyl sulfonium trifluoromethanesulfonate (TPST) of 3\% (wt.) loading was respectively used for ArF and $\mathrm{KrF}$ exposure. (See Figure 1.)
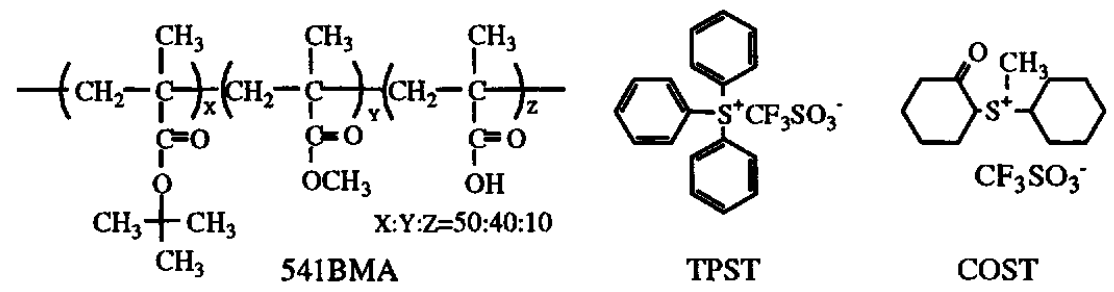

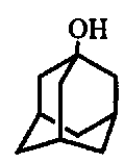

AdOH

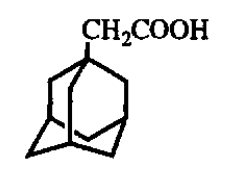

$\mathrm{AdCH}_{2} \mathrm{COOH}$<smiles>O=C(O)C1C2CC3CC(C2)C1C3</smiles>

$\mathrm{AdCOOH}$

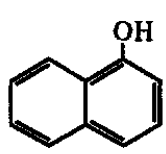

$\mathrm{NphOH}$

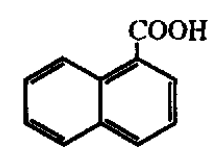

$\mathrm{NphCOOH}$

Figure 1. Terpolymer, PAGs, and additives for resist.

\subsection{Measurements}

Molecular weight (distribution) of the terpolymer was determined by gel permeation chromatography with a TOSOH HLC-8020 equipped with a refractive index detector (polystyrene standard). Transparency of the resist was measured with a JASCO VUV-200 ( $\lambda=185-300 \mathrm{~nm}$ ) using 1.0- $\mu \mathrm{m}$ thick resist films spin-coated on a quartz substrate and baked at $90^{\circ} \mathrm{C}$ for 60 seconds. Polarities of the additives were estimated by Rf values in thin layer chromatography (TLC). A reversed phase $\mathrm{C}-18$ silica gel, SPOTFILM® (Tokyo Chemical Industry Co., Ltd.) was used for TLC experiments. The spot of substrate was visualized with iodine vapor treatment. The $\mathrm{Rf}$ value is defined as follows: $\mathrm{Rf}=\mathrm{Zs} / \mathrm{Zm}$, Zs: Moving distance of a dissolved substrate, $\mathrm{Zm}$ : Moving distance of elution fluid. The more polar compounds give the higher $\mathrm{Rf}$ values in case of this reversed

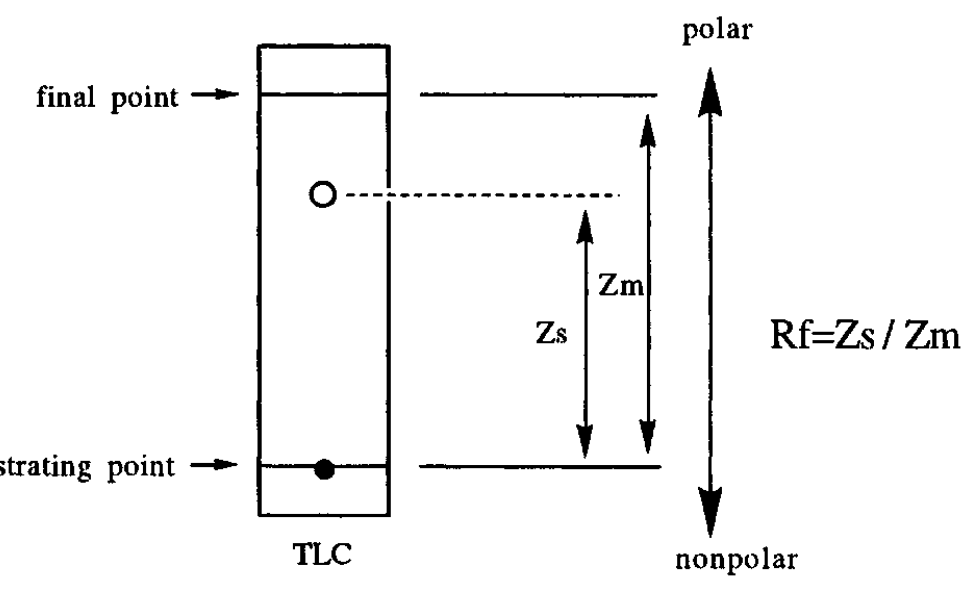

Figure 2. Calculation of Rf value. phase TLC. (See Figure 2). Tg of formulated resist was obtained with a MAC SCIENCE TGDTA-2000S (scan range $=120-300^{\circ} \mathrm{C}$ ) using the film baked cyclohexane-solution containing 
541BMA with various additives at $90^{\circ} \mathrm{C}$ for 30 minutes. A ${ }^{1} \mathrm{H}-\mathrm{NMR}$ spectrum of the terpolymer was obtained with a JEOL JNM-EX90 (90MHz).

\subsection{Lithographic Performance Evaluation}

Resist solutions were prepared by dissolving the terpolymer, PAG, and an additive into mixture solvent of cyclohexane (CH) and ethyl lactate (EL); $\mathrm{CH} / \mathrm{EL}=4 / 1$ (wt.). The solutions were filtered through $0.2-\mu \mathrm{m}$ filter and spin-coated on silicon wafers pre-treated with $1,1,1,3,3,3-$ hexamethyldisilazane (HMDS). The spin-coated wafers were pre-baked on a hotplate at $90^{\circ} \mathrm{C}$ for 60 seconds. The resist film thickness was set to $0.6-\mu \mathrm{m}$. The resist films were exposed by using an ArF prototype exposure system (Nikon; N.A.= 0.55) or a $\mathrm{KrF}$ excimer laser stepper (Nikon; N.A. $=0.50$ ), post-baked at $110^{\circ} \mathrm{C}$ for 60 seconds, developed with a TMAH aqueous solution $(0.238 \mathrm{wt} . \%)$ for 60 seconds in dip mode, and rinsed with deionized water for 5 seconds.

\subsection{Development Rate Monitor (DRM) Measurements}

Regarding 0.6- $\mu \mathrm{m}$ thick resist films exposed with the $\mathrm{KrF}$ stepper under above conditions, the dissolution behavior of the film was evaluated with DRM (Leap Simu MODEL-780MKII, LITHOTEC JAPAN) using a TMAH aqueous solution $(0.238 \mathrm{wt} . \%)$ as developer. The dissolution rate at the surface (Thickness $(\mathrm{T})=0.47-0.57-\mu \mathrm{m})$, in the middle $(\mathrm{T}=0.25-0.35-\mu \mathrm{m})$, and at the bottom $(\mathrm{T}=0.03-0.13-\mu \mathrm{m})$ was respectively collected.

\section{Results and discussion}

\subsection{Glass transition temperature}

Controlled $\mathrm{Tg}$ is indispensable for CA resists in terms of thermal durability, environmental stability[8], acid diffusion[9], inhibition of cracking. Table 1 shows the $\mathrm{Tg}$ of the formulated resists. The favorable $\mathrm{Tg}$ window is supposed to be over the range of 130 $170^{\circ} \mathrm{C}$ according to pioneer's viewpoints.[10] The terpolymer showed acceptable $\mathrm{Tg}$ of $157^{\circ} \mathrm{C}$. All investigated additives showed moderate influence upon $\mathrm{Tg}$ of the formulated resists. Slight enhancements in $\mathrm{Tg}$ might be due to hydrogen bonding between additives and the matrix terpolymer.

\subsection{Transparency of the film}

Table 1. Tg and transparency of 541BMA with and without additives.

\begin{tabular}{|c|c|c|c|}
\hline \multirow{2}{*}{ sample } & \multirow{2}{*}{$\operatorname{Tg}\left({ }^{\circ} \mathrm{C}\right)$} & \multicolumn{2}{|c|}{ transparency $(\% / \mu \mathrm{m})$} \\
\hline & & $193 \mathrm{~nm}$ & $248 \mathrm{~nm}$ \\
\hline 541BMA & 157 & 62.4 & 97.5 \\
\hline $\begin{array}{l}\text { 541BMA } \\
\text { +AdOH }(5 \%)\end{array}$ & 157 & 71.7 & 93.9 \\
\hline$+\mathrm{AdOH}(10 \%)$ & 166 & 74.3 & 95.2 \\
\hline$+\mathrm{AdCH}_{2} \mathrm{COOH}(5 \%)$ & 165 & 70.1 & 93.8 \\
\hline$+\mathrm{AdCH}_{2} \mathrm{COOH}(10 \%)$ & 170 & 69.3 & 94.3 \\
\hline$+\operatorname{AdCOOH}(5 \%)$ & 157 & 70.9 & 94.2 \\
\hline$+\operatorname{AdCOOH}(10 \%)$ & 163 & 75.4 & 95.0 \\
\hline$+\mathrm{NphOH}(5 \%)$ & 162 & 27.1 & 81.5 \\
\hline$+\mathrm{NphOH}(10 \%)$ & 169 & 12.4 & 68.8 \\
\hline$+\mathrm{NphCOOH}(5 \%)$ & 164 & 18.6 & 52.7 \\
\hline$+\mathrm{NphCOOH}(10 \%)$ & 173 & 8.5 & 32.4 \\
\hline
\end{tabular}

Transparency at 193-nm and 248-nm of the resist film was evaluated to manifest optical characteristics of five additives as shown in Table 1. Transparency of the resist film is an important factor affecting imaging properties, the photospeed and the resist profile. It was found that $\mathrm{AdOH}$, $\mathrm{AdCH}_{2} \mathrm{COOH}$, and $\mathrm{AdCOOH}$ made the resist more transparent and $\mathrm{NphOH}$ and $\mathrm{NphCOOH}$ made 
the resist more opaque. This result means that transparency of resist could be easily controlled by loading two kinds of additives. Especially, naphthalic compounds might be suitable for light-dye to ease severe standing wave effect.

\subsection{Characteristic curve, photospeed and resist contrast}

Exquisite control of the photospeed of the resist should be significant, especially in ArF lithography, from the standpoint of the throughput of semiconductor manufacturing and the optical damages in exposure system. According to a current prediction, the photospeed for ArF single layer resist ought to be tuned to $15-25 \mathrm{~mJ} / \mathrm{cm}^{2}$.[11] Characteristic curve collections were carried out with ArF exposure. The photospeed of the resists were evaluated with Eo, the dose for complete dissolution of the resist film. The resist contrast were evaluated with $\gamma$-value. Table 2 tabulates Eo, $\gamma$-value, and remaining film thickness determined from characteristic curves. All additives except AdOH enhanced Eo in a controllable degree and degraded a little $\gamma$-value. The contrast degradation is not so fatal and might be favorable in some cases because resist contrast should be tuned depending on applying feature patterns, i.e., $\mathrm{L} / \mathrm{S}, \mathrm{C} / \mathrm{H}$, dark field, or light field, etc. The photospeed enhancement should be meaningful because the relatively stolid photospeed of 541BMA $\left(39 \mathrm{~mJ} / \mathrm{cm}^{2}\right)$ could be tuned in the favorable photospeed range $\left(15-25 \mathrm{~mJ} / \mathrm{cm}^{2}\right)$. Figure 3 shows the characteristic curves of the resist films of 541BMA itself, with 5\% (wt.) and $10 \%$ (wt.) of additives.

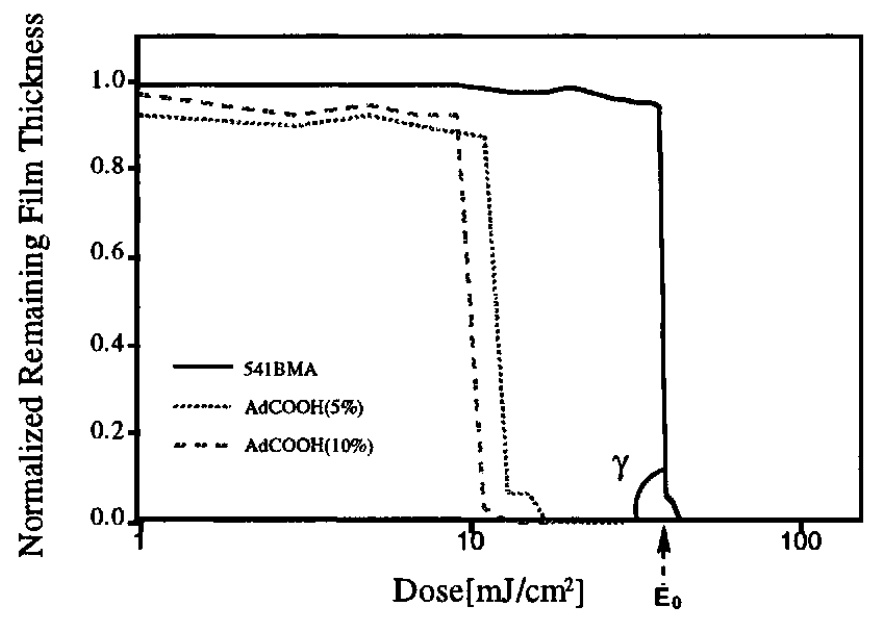

Figure 3. Representative characteristic curves for resists without and with additives of $5 \%$ (wt.) and of $10 \%$ (wt.) on ArF prototype exposure system.

The higher loading level of AdCOOH demonstrated the higher photospeed with less degradation of $\gamma$ -
Table 2. Fundamental resist properties obtained from characteristic curves.

\begin{tabular}{|c|c|c|c|}
\hline sample & $\underset{\left(\mathrm{mJ} / \mathrm{cm}^{2}\right)}{\mathrm{E}_{0}}$ & $\gamma$ & $\begin{array}{l}\text { thickness }^{\mathrm{a}} \\
(\%)\end{array}$ \\
\hline 541BMA & 39 & 35.7 & 100 \\
\hline $\begin{array}{l}\text { 541BMA } \\
\text { +AdOH }(5 \%)\end{array}$ & - & - & 96.9 \\
\hline$+\mathrm{AdOH}(10 \%)$ & - & - & 100 \\
\hline$+\mathrm{AdCH}_{2} \mathrm{COOH}(5 \%)$ & 17 & 15.8 & 97.7 \\
\hline$+\mathrm{AdCH}_{2} \mathrm{COOH}(10 \%)$ & 23 & 19.0 & 100 \\
\hline$+\operatorname{AdCOOH}(5 \%)$ & 13 & 25.1 & 98.1 \\
\hline$+\operatorname{AdCOOH}(10 \%)$ & 11 & 20.3 & 100 \\
\hline$+\operatorname{NphOH}(5 \%)$ & 17 & 14.3 & 97.9 \\
\hline$+\mathrm{NphOH}(10 \%)$ & 8 & 15.8 & 97.7 \\
\hline$+\mathrm{NphCOOH}(5 \%)$ & 29 & 24.7 & 98.3 \\
\hline$+\mathrm{NphCOOH}(10 \%)$ & 25 & 14.2 & 97.6 \\
\hline
\end{tabular}

The resist films were exposed by using an $\mathrm{ArF}$ prototype exposure system. ${ }^{a}$ Remaining film thickness. value. Table 3 summarizes the polarity estimation for the five additives. Rf and Rf (TMAH) respectively indicates the original polarity and the resultant polarity in the presence of TMAH. Judging from the Rf (TMAH), the polarity increases in the following order; $\mathrm{NphCOOH}>\mathrm{NphOH}$ 
$\mathrm{AdCOOH}>\mathrm{AdCH}_{2} \mathrm{COOH}>\mathrm{AdOH}$.

This polarity order basically makes agreement with the photospeed order shown in Table 2. This results may mean that the photospeed could be controlled by changing the polarity of additive. The most polar $\mathrm{NphCOOH}$ showed a little photospeed enhancement due to its optical disadvantage; optical density of the film containing $10 \%$ of $\mathrm{NphCOH}$ is $8.5 \% / \mu \mathrm{m}$ (See Table 1).

Table 3. Polarity of additives.

\begin{tabular}{lll}
\hline additive & $\operatorname{Rf(TMAH)~}^{\mathrm{a}}$ & $\mathrm{Rf}^{\mathbf{b}}$ \\
\hline AdOH & 0.51 & 0.50 \\
AdCH $_{2} \mathrm{COOH}$ & 0.53 & 0.47 \\
AdCOOH & 0.60 & 0.50 \\
NphOH(5\%) & 0.72 & 0.57 \\
NphCOOH(5\%) & 0.77 & 0.64 \\
\hline
\end{tabular}

${ }^{\mathrm{a}} \mathrm{MeCN} / 0.119 \%$ (wt.) TMAH aqueous solution $=70 /$ 30 (vol.). ${ }^{\mathrm{b}} \mathrm{MeCN} / \mathrm{H}_{2} \mathrm{O}=70 / 30$ (vol.).

\subsection{Dissolution behavior of the resist film}

To clarify the effect of additives on dissolution behavior, DRM measurements were executed about 541BMA, $541 \mathrm{BMA}+\mathrm{AdCH} 2 \mathrm{COOH}(20 \%)$, and 541BMA+AdCOOH(20\%). Dissolution curves of resist films were collected as shown in Figure 4. The dissolution curves were respectively examined at the surface, in the middle, and at the bottom parts inasmuch as that methodology is very useful for expectation of actual resist.[12] Moreover, each dissolution curve was separated into three partitions of (a), (b), and (c). The additives showed obvious effects on the dissolution curves, enhancement of dissolution rate in the partition (a) and narrowing
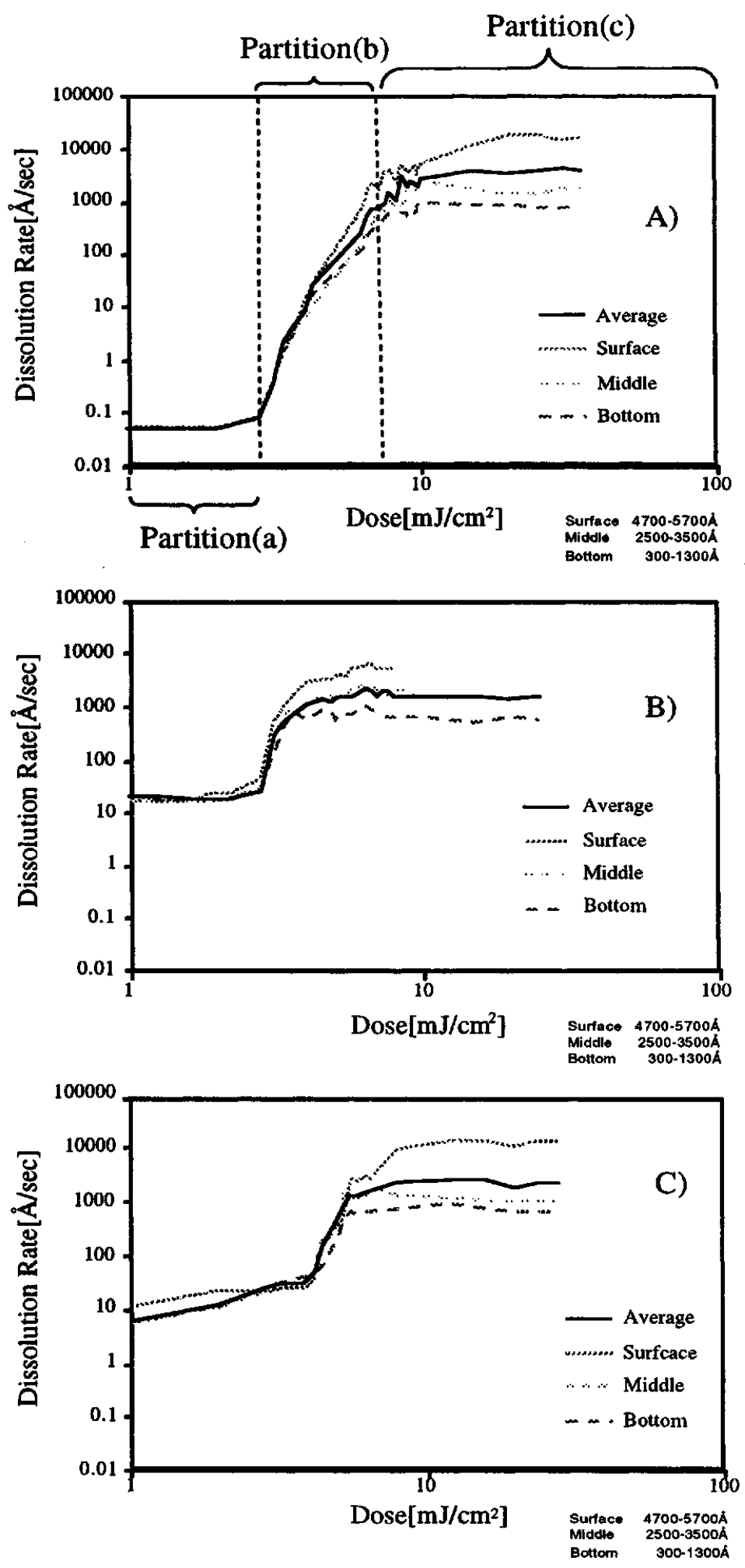

Figure 4. Dissolution rate curves for resists, $A$ ) without additive(541BMA itself), B) with $\mathrm{AdCH}_{2} \mathrm{COOH}$, and C) with AdCOOH. 
of the partition (b), but did not showed any clear effect in the partition (c). The effect of additives in the partition (a) would be meaningful for control of the resist profile, especially, for inhibition of Ttop formation. The dissolution rate of the unexposed resist implies that of surface insoluble layer caused by airborne contaminants. Therefore, extremely slow original dissolution rate might induce stubborn insoluble layer formation. The original dissolution rate of the resist were controlled by additives in the following order; 541BMA+AdCH2COOH > 541BMA+AdCOOH > 541BMA. Ttop formation would be improved by the order. In the partition (c), the dissolution rate at the surface were much higher than that in the middle and that at the bottom. That unfavorable differences might be due to the diluted TMAH developer $(0.238 \%)$ that is easily consumed with a pile of $\mathrm{COOH}$ groups of the resist.

\subsection{Resist Performances}

The resist profile was evaluated with $\mathrm{KrF}$ exposure to visualize the effect of AdCOOH and $\mathrm{AdCH}_{2} \mathrm{COOH}$ on T-top inhibition. An alicyclic polymer with $50 \mathrm{~mole} \%$ of alicyclic unit, polymer A, was used as host resin. The loading level of additives was $20 \%$ (wt.). The total amount of alicyclic carbons is summed up to $60 \%$ (wt.) supposed to be enough to achieve good etching resistance. Figure 5 showed $0.26-\mu \mathrm{m} \mathrm{L} / \mathrm{S}$ patterns with different delay times between exposure and PEB. As expected from DRM measurements, both two resists with alicyclic additives hardly gave T-top formation in comparison of that without additive. The resist comprising $\mathrm{AdCOOH}$ showed good profile even after 30 minutes of delay time. On the contrary, the resist comprising $\mathrm{AdCH}_{2} \mathrm{COOH}$ yielded inferior resist profiles owing to too much enhanced original dissolution rate.

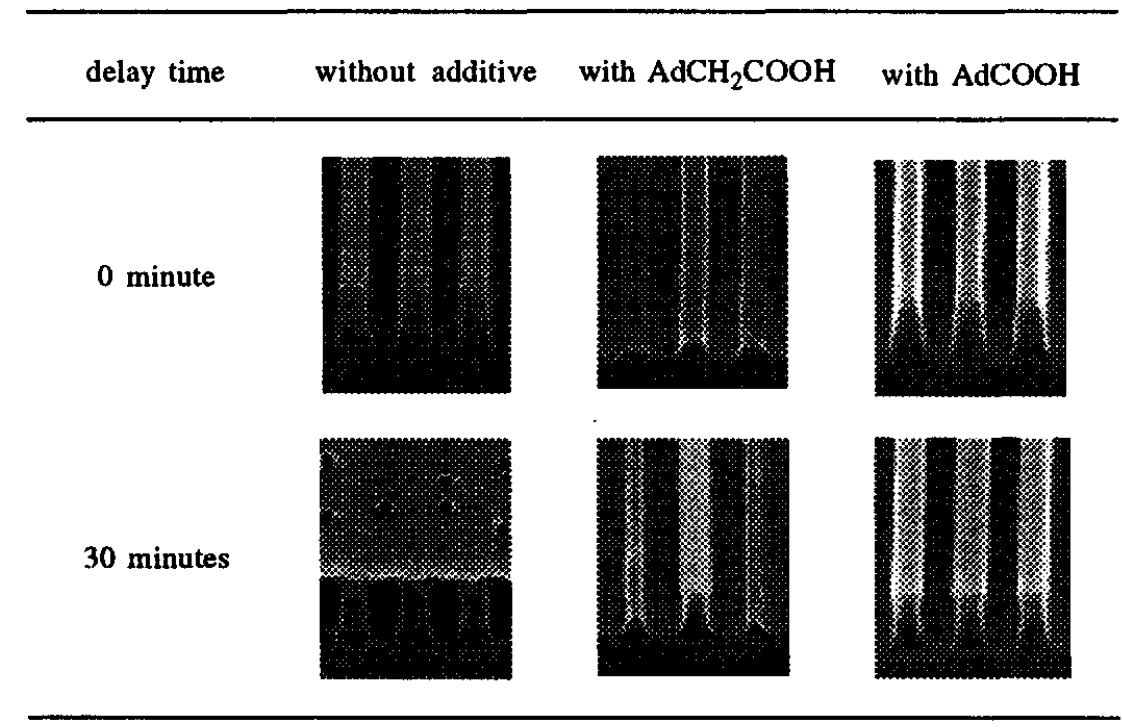

Figure 5. SEM photograph of $0.26-\mu \mathrm{m} \mathrm{L \& S}$ resist profile on $\mathrm{KrF}$ exposure system.

\section{Conclusion}

Several effects of small molecular additives were elucidated in terms of the transparency, the photospeed, the resist contrast, the dissolution behavior, and the resist profile. Taking advantage of those specific effects, new three component single layer ArF resist comprising an acrylic polymer and a small molecule with acidic functional group, and a PAG was designed. One of the three component systems, indeed, showed good imaging performance with $\mathrm{KrF}$ exposure. Loading the 
additives would compensate for some inherent defects of matrix acrylic polymers and consequently allow considerable latitude in resist design of ArF CA resist.

\section{Acknowledgments}

The authors would like to thank Nikon Corporation for offering the opportunity of ArF exposure. They also would like to thank Mr. Kazuhiro Shimada for his support on DRM measurement and all their colleagues in Japan Synthetic Rubber(JSR) Co., Ltd. for supports on this work.

\section{Reference}

1. R. D. Allen, G. M. Wallraff, W. D. Hinsberg, W E. Conley, and R. R. Kunz, J. Photopolym. Sci. Tech., 6 (4) (1993) 575; R. D. Allen, G. M. Wallraff, W. D. Hinsberg, W. E. Conley, and R. R. Kunz, Solid State Technology, 36 (1993) 53.

2. Y. Kaimoto, K. N., S. Takechi, and N. Abe, Proc. SPIE, 1672 (1992) 66; S. Takechi, Y. K., K. Nozaki, and N. Abe, J. Photopolym. Sci. Technol., 5 (1992) 439.

3. M. Endo, K. H., K. Yamashita, A. Kutsuyama, T. Matsuo, Y. Tani, M. Sasago, and N. Nomura, IEDM Tech. Digest, (1992) 45.

4. K. Nakano, K. M., S. Iwasa, J. Yano, Y. Ogura, and E. Hasegawa, Proc. SPIE, 2195 (1993) 194.

5. R. D. Allen, G. M. Wallraff, R. A. DiPietro, D. C. Hofer, and R. R. Kunz, J. Photopolym. Sci. Technol., 7 (3) (1994) 507; R. D. Allen, G. M. Wallraff, R. A. Dipietro, D. C. Hofer, and R. R. Kunz, Proc. 10th International Conference Photopolymers, 6 (4) (1994) 575.

6. R. D. Allen, G. M. Wallraff, R. A. DiPietro, and D. C. Hofer, Proc. SPIE, 2438 (1995) 474.

7. R. D. Allen, G. M. Wallraff, W. D. Hinsberg, and L. L. Simpson, J. Vac. Sci. Tehcnol., B (9) (1991) 3357.

8. H. Ito, G. B., D. Hofer, R. Sooriyakumaran, K. Petrillo, and D. Seeger, J. Photopolym. Sci. Technol., 7 (1994) 433.

9. R. D. Allen, G. M. Wallraff, R. A. Dipietro, D. C. Hofer, and R. R. Kunz, Proc. 10th International Conference Photopolymers, 6 (4) (1994) 575.

* They mentioned that long range acid diffusion on the scale of millimeters was observed when the exposed film were baked above Tg. No experimental data were demonstrated.

10. R. D. Allen, G. M. Wallraff, D. C. Hofer, R. R. Kunz, S. C. Palmateer, and M. W. Horn Microlithography World, (1995) 21.

11. M. Hibbs, R. R. K. Solid State Technolgy, 38 (1995) 69.

12. H. Miyamoto, T. N., K. Inomata, T. Ota, and A. Tsuji, Proc. SPIE, 2488 (1995) 223. 